\title{
Diet and behavioral problems at school in Norwegian adolescents
}

\author{
Nina Øverby* and Rune Høigaard
}

Department of Public Health, Sport and Nutrition, Faculty of Health and Sport Sciences, University of Agder, Norway

Abstract

Background: Discussion about dietary factors in relation to behavioral problems in children and adolescents has been going on for a long time.

Objective: The aim of this study was to investigate the cross-sectional relation between diet and self-reported behavioral problems at school in adolescents in the southern part of Norway.

Design: In total, 475 ninth- and tenth-grade students (236 boys and 239 girls) out of 625 eligible students from four different secondary schools in three different communities in Vest-Agder County, Norway, participated, giving a participation rate of $77 \%$. The students filled in a questionnaire with food frequency questions of selected healthy (e.g. fruits, vegetables, and fish) and unhealthy (e.g. sweets, sugar-sweetened beverages, and crisps) food items, questions of meal frequency, and four questions regarding behavioral problems at school.

Results: Having breakfast regularly was significantly associated with decreased odds of behavioral problems (OR: $0.29(0.15-0.55), p \leq 0.001)$. A high intake of unhealthy foods, such as sugar-sweetened soft drinks (OR: $2.8(1.06-7.42), p=0.03)$ and sweets (OR: $2.63(1.39-4.98), p=0.003)$, was significantly associated with increased odds of behavioral problems. At the same time, a high intake of fruits was associated with decreased odds of behavioral problems in Norwegian adolescents (OR: $0.30(0.10-0.87), p=0.03)$. All ORs are adjusted for sex and BMI.

Conclusions: This study shows that having an optimal diet and not skipping meals are associated with decreased odds of behavioral problems at school in Norwegian adolescents. Hence, it is important to improve the dietary intake and meal pattern of Norwegian adolescents. The cross-sectional design of this study limits any causal interpretations of the results of the study.

Keywords: adolescents; behavioral problems; diet; meal pattern

Received: 20 January 2012; Revised: 22 May 2012; Accepted: I June 2012; Published: 28 June 2012

\section{A} discussion about how dietary factors affect adolescents' behavior, especially in relation to hyperactivity and behavioral problems $(1,2)$, has been going on for a long time. Balanced nutrition is important during childhood and adolescence, which are periods of growth, development of body functions, and social cognitive ability (3). Behavioral and social skills achieved in childhood may determine the person's ability to cope with the many demands of modern society (4). Increased availability of processed food, rich in sugar and fat, has led to its increased intake by children and adolescents (5). A diet high in sugar may lead to massive secretion of insulin, resulting in hypoglycemia $(3,6)$. This stimulates an increase in epinephrine, leading to activation of nervous reactions and may lead to hyperactivity disorder behaviors $(3,6)$. Recent results from the ALSPAC study, where food patterns were identified after principal components analyses, show that children eating a diet high in junk food, e.g., high-fat processed foods (burgers) and snack food (crisps and sweets), in early childhood were more likely to be hyperactive at age 7 (2). However, there is still controversy regarding the association between sugar and hyperactivity, and Kim and Chang found no association between sugar intake and behavior (3). Another dietary trend among adolescents is skipping meals $(7,8)$, and some studies found that skipping breakfast may be related to mental distress (9), which may lead to behavioral problems. Behavior at school is specifically important, as this is the place for learning and student behavior affects learning and the social environment at school. Little is known about the relation between diet and behavior at school in Norwegian adolescents. Given the poor nutritional habits (10) in adolescents in Norway, we wanted to examine the link 
between self-reported meal patterns, food intake, and behavioral problems at school in Norwegian adolescents. Behavioral problems at school range from shouting to having to leave the classroom because of bullying.

\section{Methods}

\section{Subjects}

This study is part of the 'School Achievement Study' conducted by the University of Agder and Sørlandet Resource Centre. In 2010, 625 ninth- and tenth-grade students, from four different secondary schools in three different municipalities in Vest-Agder County, were invited to participate by filling in a questionnaire. Of these, 482 students returned the questionnaires giving a participation rate of $77 \%$, and 475 students were included in the statistical analysis - 236 boys and 239 girls. Seven questionnaires were excluded because of many shortcomings or incorrect completion. The mean age for both genders was 14.6.

\section{Procedure}

This study was conducted in January 2010. The best suited participant schools in the county, representing both urban and rural municipalities, were selected by Sørlandet Resource Centre. Sørlandet Resource Centre contacted the principals at the different schools for their participation. All four schools that were contacted agreed to participate - two schools from the main city (Kristiansand) in the county and one secondary school each from the two rural municipalities were included. The students filled in the questionnaire during a school lesson in the presence of a master student and a project worker. Before the questionnaires were handed out, the participants were informed that their responses would be treated as anonymous and that it was voluntary to participate. The students were given both oral and written instructions on how to fill in the questionnaire. The project worker helped the students with any questions. After filling out the questionnaire, the students returned it to the project worker in a sealed envelope.

\section{Instruments}

The questionnaire included questions about how students behave in school and their dietary intake and meal frequencies. To measure the students' behavioral problem at school, we adopted items from Roland (11) and developed a four-item, self-reported questionnaire. The four items were, 'Do you make so much noise in class that the teachers yell at you?', 'Are you expelled from class because you make too much noise?', 'Does your teacher write down your name because of bad behavior?', and 'Do you disturb the class to such an extent that other students in your class can't pay attention?' All questions had five response categories, 'Never', 'Seldom', 'Some- times', 'Often', and 'Very often' (range: 1-5). A sum score of these questions was made (range: 4-20) with a high number indicating more problems. This sum score was dichotomized into those not having (score: 4-11) and those having behavioral problems at school (score: 12-20). In this study, the Cronbach's $\alpha$ for the scale behavioral problems at school was 0.85 , indicating high reliability.

Diet was assessed by a food frequency questionnaire comprising 23 components, both food items and drinks. The questions had eight different response alternatives, ranging from never or seldom to four times or more per day for food items and seven glasses or more per day for beverages. The questionnaire had been validated in a national dietary study among Norwegian children and adolescents (12). The response alternatives were dichotomized into having food often or seldom. Having fruits and vegetables $(\mathrm{F} \& \mathrm{~V})$ twice a day or more often was categorized as often. Having fish one-three times per week or more was categorized as often. Having candies, chocolate, and savory snacks four-six times per week or more often was categorized as often. The quantity of intake was not asked for. In the analysis, the food items were segregated between healthy and unhealthy food items. Healthy food items included vegetables, fruits, and fish. Unhealthy food items included sugar-sweetened soft drinks, sweets, chocolate, savory snacks, pizza, and burger or hot dogs. Meal frequency was assessed by questions like, 'How often do you have breakfast each week?' The same was asked for lunch, dinner, and evening meals. Response alternatives ranged from never or seldom to seven days a week, and in the statistical analysis these were dichotomized into having meals five times a week or less and having meals six times a week or more, as done by Øverby et al. (13).

\section{Definitions}

Self-reported weight and height were used to calculate BMI $\left(\mathrm{kg} / \mathrm{m}^{2}\right)$. To estimate the prevalence of overweight, the international cutoff points for BMI for overweight were used (14).

\section{Data analysis}

In Table 1, the results are presented with means and standard deviations (SD) and percentage of participants. Statistical analyses are independent sample $t$-tests and chi-square. Multiple logistic regressions were used to explore the relation between behavioral problems at school and meal patterns and unhealthy and healthy food items. The dependent variable was whether the respondent had behavioral problems at school and was dichotomized into having these or not. All meals (breakfast, lunch, dinner, and evening meals) and healthy and unhealthy food items were run in separate models adjusting for gender and BMI. Adjustments were done 
Table 1. Description of participants

\begin{tabular}{|c|c|c|c|}
\hline & Boys $(n=236)$ & Girls $(n=239)$ & $p^{c}$ \\
\hline Age (year) mean (SD) & $14.6(0.56)$ & I4.6 (0.57) & 0.633 \\
\hline Behavioral problems & $41(17.9)$ & $28(11.8)$ & 0.064 \\
\hline Overweight (\%) & $30(16.1)$ & I5 (8.0) & 0.015 \\
\hline Breakfast $^{\mathrm{a}}(\%)$ & $169(76.8)$ & $152(66.1)$ & 0.012 \\
\hline Lunch $^{\mathrm{a}}(\%)$ & $129(59.2)$ & $132(50.6)$ & 0.784 \\
\hline Dinner $^{a}(\%)$ & $197(90.4)$ & $193(84.3)$ & 0.054 \\
\hline Supper ${ }^{\mathrm{a}}(\%)$ & $146(67.0)$ & $116(51.5)$ & $\leq 0.001$ \\
\hline Vegetables $^{\mathrm{b}}(\%)$ & $18(8.5)$ & $9(3.9)$ & 0.046 \\
\hline Fruits $^{\mathrm{b}}(\%)$ & $35(16.4)$ & $64(28.6)$ & 0.002 \\
\hline Fish $^{\mathrm{b}}(\%)$ & $99(46.3)$ & $103(45.8)$ & 0.919 \\
\hline $\begin{array}{l}\text { Sugar-sweetened soft } \\
\text { drinks }^{\mathrm{b}}(\%)\end{array}$ & I 80 (84.9) & 145 (65.9) & $\leq 0.00 \mathrm{I}$ \\
\hline Sweets ${ }^{\mathrm{b}}(\%)$ & 57 (26.9) & 42 (18.7) & 0.040 \\
\hline Chocolate $^{\mathrm{b}}(\%)$ & $47(22.1)$ & $4 \mid(18.1)$ & 0.294 \\
\hline Savory snacks ${ }^{\mathrm{b}}(\%)$ & $46(21.8)$ & $18(8.0)$ & $\leq 0.001$ \\
\hline Pizza $^{\mathrm{b}}(\%)$ & $24(11.3)$ & $14(6.2)$ & 0.059 \\
\hline Burger/Hot dogs ${ }^{\mathrm{b}}(\%)$ & $14(6.6)$ & $10(4.4)$ & 0.317 \\
\hline
\end{tabular}

Proportion having behavioral problems at school, having meals regularly ${ }^{\mathrm{a}}$ and having healthy and unhealthy food items often ${ }^{\mathrm{b}}(n[\%])$.

a'Having meals regularly' was defined as having meals six times a week or more.

'bHaving healthy foods often' was defined as having F\&V twice a day or more often, and having fish one three times per week or more. 'Having unhealthy foods often' was defined as having food four-six times a week or more often.

Independent two-sample $t$-test continuous variables and Chi-square for categorical variables. Overweight is defined by Cole et al. 2000 (14).

according to literature. Odds ratios are presented in the tables with $95 \%$ confidence intervals (CI). All $p$-values are two-sided and a $5 \%$ level of significance was used. All statistical analyses were performed with SPSS 16.0 (SPSS Inc., Chicago, IL).

\section{Results}

Characteristics of study participants are presented in Table 1. More boys than girls were categorized as overweight $(16 \%$ vs. $8 \%, p=0.015)$. There were also gender differences with regard to meal patterns and food consumption. More girls skip breakfast and evening meals compared to boys ( $77 \%$ vs. $66 \%, p=0.01)$. High intake of unhealthy foods was defined as having food four-six times per week or more, whereas a high intake of $\mathrm{F} \& \mathrm{~V}$ was defined as having food items twice a day or more often. More boys reported a high intake of vegetables ( $8 \%$ vs. $4 \%, p<0.05)$ and a low intake of fruits $(84 \%$ vs. $71 \%, p<0.01)$ compared to girls. More boys than girls have a high intake of food items categorized as unhealthy, such as sugar-sweetened soft drinks, sweets, and savory snacks (Table 1). Table 2 presents adjusted results for meal frequencies' association with behavioral
Table 2. Adjusted odds ratio (OR) and 95\% CI for behavioral problems at school in relation to meal pattern ${ }^{\mathrm{a}}$

\begin{tabular}{lclc}
\hline & $n$ & $\mathrm{OR}^{\mathrm{b}}(95 \% \mathrm{Cl})$ & $P$ \\
\hline $\begin{array}{l}\text { Breakfast } \\
\text { Seldom }\end{array}$ & $10 \mathrm{I}$ & 1.0 & \\
Often & 269 & $0.29(0.15-0.55)$ & $\leq 0.00 \mathrm{I}$ \\
$\begin{array}{l}\text { Lunch } \\
\text { Seldom }\end{array}$ & 142 & 1.0 & \\
Often & 225 & $0.65(0.35-0.2 \mathrm{I})$ & 0.176 \\
$\begin{array}{l}\text { Dinner } \\
\text { Seldom }\end{array}$ & 43 & 1.0 & \\
Often & 324 & $0.52(0.22-1.23)$ & 0.137 \\
Supper & & & \\
Seldom & 149 & 1.0 & 0.378 \\
Often & 218 & $0.75(0.40-1.42)$ & \\
\hline
\end{tabular}

a'Having meals seldom' is defined as having meals five times a week or less. 'Having meals often' is defined as having meals six times a week or more often.

${ }^{\mathrm{b}}$ Adjusted for sex and BMI.

problems at school. Having breakfast regularly was significantly associated with decreased odds of behavioral problems at school (OR: $0.29(0.15-0.55), p \leq 0.01)$. Having lunch, dinner, and evening meals regularly was not significantly associated with decreased odds of behavioral problems at school (Table 2). Adjusted results for healthy food items' association with behavioral problems are presented in Table 3. Those who reported eating fruits (OR: $0.30(0.10-0.87), p=0.027)$ and fish (OR: $0.47(0.24-0.91), p=0.025)$ regularly had lower odds of behavioral problems at school. No association between intake of vegetables and behavioral problems at school was found. However, a high intake of unhealthy foods (sugar-sweetened soft drinks, sweets, chocolate,

Table 3. Adjusted odds ratio (OR) and 95\% CI for behavioral problems at school in relation to intake of healthy food items ${ }^{\mathrm{a}}$

\begin{tabular}{|c|c|c|c|}
\hline & \multicolumn{3}{|c|}{ Behavioral problems } \\
\hline & $N$ & OR $(95 \% \mathrm{Cl})$ & $P$ \\
\hline \multicolumn{4}{|l|}{ Vegetables } \\
\hline Once a day or less & 345 & 1.0 & \\
\hline Twice a day or more & 23 & $1.44(0.46-4.49)$ & 0.528 \\
\hline \multicolumn{4}{|l|}{ Fruit } \\
\hline Once a day or less & 282 & 1.0 & \\
\hline Twice a day or more & 84 & $0.30(0.10-0.87)$ & 0.027 \\
\hline \multicolumn{4}{|l|}{ Fish } \\
\hline I-3 times per month or less & 201 & 1.0 & \\
\hline I-3 times per week or more & 167 & $0.47(0.24-0.91)$ & 0.025 \\
\hline
\end{tabular}

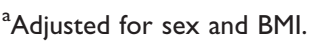


savory snacks, pizza, and hotdogs) was significantly associated with increased odds of behavioral problems at school (Table 4).

\section{Discussion}

This study shows that adolescents who frequently have breakfast and a moderate intake of fruit and fish have reduced odds of behavioral problems at school. Further, the study shows that adolescents who have a high intake of unhealthy food items have increased odds of behavioral problems at school. To our knowledge, these relations have not been shown earlier in this age group of Norwegian adolescents.

Few studies explore the relation between behavior problems and meal frequency or skipping of breakfast (9). Some studies state that having breakfast regularly has a positive impact on mental health $(8,15)$. The most accepted explanation for this relation is the benefits of energy intake after a night time fast. This may improve mood, memory, and academic performance (16). Another benefit of having breakfast is the intake of essential micronutrients, which have a positive effect on likely health concerns, such as affective disorders, hyperactivity, and behavioral problems $(1,4,17)$. Lien found that Norwegian adolescents having breakfast regularly had reduced mental distress (9). One explanation for this finding can be that having breakfast reduces cortisol levels (at least in adults) (18). The finding that having

Table 4. Adjusted odds ratio (OR) and 95\% CI for behavioral problems at school in relation to intake of unhealthy food items ${ }^{a}$

\begin{tabular}{|c|c|c|c|}
\hline & \multicolumn{3}{|c|}{ Behavioral problems } \\
\hline & $N$ & OR $(95 \% \mathrm{Cl})$ & $P$ \\
\hline \multicolumn{4}{|l|}{ Sugar-sweetened soft drinks } \\
\hline I-3 times per month or less & 86 & 1.0 & \\
\hline I-3 times per week or more & 271 & $2.80(1.06-7.42)$ & 0.039 \\
\hline \multicolumn{4}{|l|}{ Sweets } \\
\hline I-3 times per week or less & 279 & 1.0 & \\
\hline 46 times per week or more & 87 & $2.63(1.39-4.98)$ & 0.003 \\
\hline \multicolumn{4}{|l|}{ Chocolate } \\
\hline I-3 times per week & 295 & 1.0 & \\
\hline 46 times per week & 73 & $4.34(2.26-8.36)$ & $\leq 0.00 \mathrm{I}$ \\
\hline \multicolumn{4}{|l|}{ Potato chips } \\
\hline I-3 times per week & 310 & 1.0 & \\
\hline 46 times per week & 56 & $3.36(0.4 I-1.54)$ & $\leq 0.001$ \\
\hline \multicolumn{4}{|l|}{ Pizza } \\
\hline I-3 times per week & 334 & 1.0 & \\
\hline 46 times per week & 32 & $3.54(1.54-8.14)$ & 0.003 \\
\hline \multicolumn{4}{|l|}{ Hamburger/hot dogs } \\
\hline I-3 times per week & 348 & 1.0 & \\
\hline 46 times per week & 20 & $3.25(1.17-8.99)$ & 0.023 \\
\hline
\end{tabular}

${ }^{\text {a } A d j u s t e d ~ f o r ~ s e x ~ a n d ~ B M I . ~}$ breakfast reduces mental distress complements our finding of reduced odds for behavioral problems when having breakfast regularly. In addition to reducing mental distress, breakfast is associated with a range of positive outcomes, including better school attendance, academic performance, nutrient intake, and healthier body weight $(19,20)$. So, although causality cannot be stated on the relation between breakfast and behavioral problems in the current study, promoting breakfast would be beneficial.

A recent Australian study found that children with behavior difficulties and low levels of prosocial behaviors and from poorly functioning households consumed fewer servings of $\mathrm{F} \& \mathrm{~V}$ than children who did not experience any environmental stressors or behavioral problems (21). This is in line with our findings regarding fruit intake, which is related to behavioral problems at school. However, we did not find an association between intake of vegetables and behavioral difficulties. This might be explained by the low intake of vegetables in Norwegian children and adolescents in general (10), leading to small differences in intake between groups. Intake of fish and behavior problems has mostly been discussed in relation to omega-3-fatty acids. Early studies by Stevens et al. found that a greater number of behavior problems were reported in subjects with lower total omega-3-fatty acid concentrations (22). A placebo-controlled trial with 166 schoolchildren in Japan investigating whether fish oil supplements affected school children's aggression levels found that there was a possibility that changes in fatty acid intake might affect physical aggression, especially in girls (23). Furthermore, a review on fish oils and aggression concludes that 11 of 14 studies found an association between fish oils and aggression (24). The mechanisms as to how fish oils affect aggression or hostility is not yet clear; however, a possible mechanism is activation of the serotonergic neuron system (24). On exploring diet and attention deficit or hyperactivity disorder (ADHD), an Australian study did not find any association between fatty acids and ADHD symptoms but found that children with ADHD consumed half the amount of fish or seafood compared to the controls (25). This is in line with what is reported in this study in relation to fish consumption and behavioral problems.

Most controversy regarding diet and behavioral problems (especially ADHD) has been found in relation to sugar and junk food $(4,26)$. For many years, teachers and parents have claimed that high sugar intake leads to attention and conduct problems in children (27). In 2009, the ALSPAC reported that children eating a diet high in 'junk food' in early childhood were more likely to be in the top $33 \%$ on the hyperactivity subscale at age 7 (2); however, this was not replicated in 2011 (28). A Norwegian study by Lien et al. among adolescents aged 15 and 16 showed that there was a dose-response relationship 
between hyperactivity score and number of soft drinks consumed (27). Furthermore, intake of soft drinks was associated with higher odds of mental distress and conduct problems (27). This is in line with the results of this study. The study of Lien et al. is one of the few studies assessing the relation between sugar intake and mental health problems (27), not just focusing on ADHD. The effect of sugar on mental health may not be direct but could be moderated by other nutritional factors, such as micronutrients (1). A study in Norwegian adolescents found that high intake of added sugar displaced intake of micronutrients (5).

With the cross-sectional design of this study, one cannot state any causality, and well-designed longitudinal studies are needed. An Australian longitudinal study from 2011 found that a healthy diet yielded better mental health, and that an unhealthy diet led to poor mental health (29), supporting the results of this study. Other longitudinal studies focusing more specifically on behavioral problems, including assessment of the whole diet, where one can calculate energy and micronutrient intake, are needed.

There are several other limitations that need to be considered when interpreting the results of this study. First, the selection of schools was not done systematically, it was a convenient sample implicating that the generalization of the results may be limited. Second, although validated, the dietary frequency questionnaires often report an overestimation of food intake. Furthermore, the quantity of intake was not estimated. However, a validation study among 9- and 13-year olds showed that the food frequency questionnaire (FFQ) was able to identify high and low consumers of food intake and had a moderate capability to rank individuals according to food intake (12). Finally, there was no assessment of socioeconomic status, physical activity, sleep, and drug abuse, which may be relevant factors regarding behavioral problems along with parenting style.

However, the results from this study clearly show that having a healthy diet is related to having reduced odds of behavioral problems at school. The literature shows that behavioral problems at school are related to school dropout (30). School dropout is a public health issue, as research shows that good education promotes good health and disparity in health and educational achievements are closely linked (31). In addition, as a healthy diet is well known to be related to optimal health (32), promoting a healthy diet, including both dietary intake and meal pattern, is important in these age groups, with regard to behavior, school achievement, and future health.

\section{Conclusion}

This study shows that adolescents who frequently have breakfast and a moderate intake of fruit and fish have reduced odds of behavioral problems at school. Furthermore, the study shows that adolescents who have a high intake of unhealthy food items have increased odds of behavioral problems at school. A longitudinal study to find causality between dietary intake and behavioral problems at school is recommended.

\section{Acknowledgement}

The authors thank Sigve Mathisen, Audhil Noslid, and Kjell Hodne from Sørlandet Resource Centre in Norway and Eva Ludemann from the University of Agder for their contributions to this project.

\section{Conflict of interest and funding}

The authors have not received any funding or benefits from industry or elsewhere to conduct this study.

\section{References}

1. Benton D. Micronutrient status, cognition and behavioral problems in childhood. Eur J Nutr 2008; 47(Suppl 3): 38-50.

2. Wiles NJ, Northstone K, Emmett P, Lewis G. 'Junk food' diet and childhood behavioural problems: results from the ALSPAC cohort. Eur J Clin Nutr 2009; 63: 491-8.

3. Kim Y, Chang H. Correlation between attention deficit hyperactivity disorder and sugar consumption, quality of diet, and dietary behavior in school children. Nutr Res Pract 2011; 5: 236-45.

4. Bellisle F. Effects of diet on behaviour and cognition in children. Br J Nutr 2004; 92(Suppl 2): 227-32.

5. Overby NC, Lillegaard IT, Johansson L, Andersen LF. High intake of added sugar among Norwegian children and adolescents. Public Health Nutr 2004; 7: 285-93.

6. Dykman KD, Dykman RA. Effect of nutritional supplements on attentional-deficit hyperactivity disorder. Integr Physiol Behav Sci 1998; 33: 49-60.

7. Nicklas TA, Morales M, Linares A, Yang SJ, Baranowski T, De MC, et al. Children's meal patterns have changed over a 21year period: the Bogalusa Heart Study. J Am Diet Assoc 2004; 104: 753-61.

8. Rampersaud GC, Pereira MA, Girard BL, Adams J, Metzl JD. Breakfast habits, nutritional status, body weight, and academic performance in children and adolescents. J Am Diet Assoc 2005; 105: 743-60.

9. Lien L. Is breakfast consumption related to mental distress and academic performance in adolescents? Public Health Nutr 2007; 10: $422-8$.

10. Øverby N, Andersen LF. Ungkost 2000 national dietary study among students in 4th and 8th grade. Oslo: Directorate of Health and Social Affairs; 2002.

11. Roland E. School influences on bullying. Doctoral thesis, Durham University; 1998: Available at Durham E-Theses Online: http://etheses.dur.ac.uk/1047/

12. Lillegaard IT, Øverby NC, Andersen LF. Evaluation of a short food frequency questionnaire used among children and adolescents. Food Nutr Res 2012; 56: 6399.

13. Øverby NC, Margeirsdottir HD, Brunborg C, DahlJorgensen K, Andersen LF. Sweets, snacking habits, and skipping meals in children and adolescents on intensive insulin treatment. Pediatr Diabetes 2008; 9: 393-400. 
14. Cole TJ, Bellizzi MC, Flegal KM, Dietz WH. Establishing a standard definition for child overweight and obesity worldwide: international survey. BMJ 2000; 320: 1240-3.

15. Chen X, Sekine M, Hamanishi S, Yamagami T, Kagamimori S. Associations of lifestyle factors with quality of life (QOL) in Japanese children: a 3-year follow-up of the Toyama Birth Cohort Study. Child Care Health Dev 2005; 31: 433-9.

16. Smith AP. The concept of well-being: relevance to nutrition research. Br J Nutr 2005; 93(Suppl 1): 1-5.

17. Gesch CB, Hammond SM, Hampson SE, Eves A, Crowder MJ. Influence of supplementary vitamins, minerals and essential fatty acids on the antisocial behaviour of young adult prisoners. Randomised, placebo-controlled trial. Br J Psychiatry 2002; 181: $22-8$.

18. Smith AP. Stress, breakfast cereal consumption and cortisol. Nutr Neurosci 2002; 5: 141-4.

19. Hoyland A, Dye L, Lawton CL. A systematic review of the effect of breakfast on the cognitive performance of children and adolescents. Nutr Res Rev 2009; 22: 220-43.

20. Ni MC, Turley M, Gorton D, Jiang Y, Michie J, Maddison R, et al. Effects of a free school breakfast programme on school attendance, achievement, psychosocial function, and nutrition: a stepped wedge cluster randomised trial. BMC Public Health 2010; 10: 738

21. Renzaho AM, Kumanyika S, Tucker KL. Family functioning, parental psychological distress, child behavioural problems, socio-economic disadvantage and fruit and vegetable consumption among 4-12 year-old Victorians, Australia. Health Promot Int 2011; 26: 263-75.

22. Stevens LJ, Zentall SS, Abate ML, Kuczek T, Burgess JR. Omega-3 fatty acids in boys with behavior, learning, and health problems. Physiol Behav 1996; 59: 915-20.

23. Itomura M, Hamazaki K, Sawazaki S, Kobayashi M, Terasawa K, Watanabe S, et al. The effect of fish oil on physical aggression in schoolchildren - a randomized, double-blind, placebo-controlled trial. J Nutr Biochem 2005; 16: 163-71.
24. Hamazaki T, Hamazaki K. Fish oils and aggression or hostility. Prog Lipid Res 2008; 47: 221-32.

25. Ng KH, Meyer BJ, Reece L, Sinn N. Dietary PUFA intakes in children with attention-deficit/hyperactivity disorder symptoms. Br J Nutr 2009; 102: 1635-41.

26. Benton D. The influence of children's diet on their cognition and behavior. Eur J Nutr 2008; 47(Suppl 3): 25-37.

27. Lien L, Lien N, Heyerdahl S, Thoresen M, Bjertness E. Consumption of soft drinks and hyperactivity, mental distress, and conduct problems among adolescents in Oslo, Norway. Am J Public Health 2006; 96: 1815-20.

28. Peacock PJ, Lewis G, Northstone K, Wiles NJ. Childhood diet and behavioural problems: results from the ALSPAC cohort. Eur J Clin Nutr 2011; 65: 720-6.

29. Jacka FN, Kremer PJ, Berk M, de Silva-Sanigorski AM, Moodie M, Leslie ER, et al. A prospective study of diet quality and mental health in adolescents. PLoS One 2011; 6(9): e24805.

30. Henry KL, Knight KE, Thornberry TP. School disengagement as a predictor of dropout, delinquency, and problem substance use during adolescence and early adulthood. J Youth Adolesc 2012; 41: 156-66.

31. Freudenberg N, Ruglis J. Reframing school dropout as a public health issue. Prev Chronic Dis 2007; 4: A107.

32. World Health Organization. Diet, nutrition and the prevention of chronic diseases. Report of a Joint WHO/FAO Expert Consultation, Technical Report Series, No. 916. Geneva: World Health Organization; 2003.

\section{*Nina Øverby}

Department of Public Health, Sport and Nutrition

Faculty of Health and Sport Sciences

University of Agder

4604 Kristiansand

Norway

Email: nina.c.overby@uia.no 